\title{
The role of the psychologist in the veterans administration's patient aligned care team and huddle: A review, practical recommendations, and a call to action
}

\section{Rodrigo Velezmoro}

\author{
C.W. Bill Young VAMC, Bay Pines VA Healthcare System, Bay Pines, FL, USA
}

\begin{abstract}
The Veterans Administration (VA)'s Patient Aligned Care Team (PACT) model has been a cornerstone of primary care in the VA healthcare system and has indicated the need for an organizational cultural shift towards interdisciplinary care. Most of the focus in PACT has been on the traditional providers of the medical model, with little attention focused on the role of the psychologist. This paper examines how psychologists can assist in the PACT model and, in particular, within the team VA huddle. Literature on the PACT model, mental health in PACT, and the advantages of the huddle are reviewed. Lessons learned within a large VA clinic are also discussed. Psychologists' ability to be a clinician, teambuilder, and system specialist is discussed and how it benefits the PACT and the huddling process. Practical recommendations are made for how to best assist during the huddle, and how to advocate for both the huddle, and for a broader cultural shift in care.
\end{abstract}

\section{Introduction}

For many years, the medical field was dominated by a treatment approach that emphasized providers working in silos (Long,

Correspondence: Rodrigo Velezmoro, C.W. Bill Young VAMC, Bay Pines VA Healthcare System, 10000 Bay Pines Blvd. Bay Pines, FL 33744, USA.

E-mail: Rodrigo.Velezmoro2@VA.gov

Key words: Huddle, Interdisciplinary, Veterans Administration, Teams.

Conflict of interest: the author declares no potential conflict of interest.

Funding: this material is the result of work supported with resources and the use of facilities at the Bay Pines VA Healthcare System. The contents of this publication do not represent the views of the Department of Veterans Affairs or the United States Government.

Received for publication: 2 March 2018.

Revision received: 31 July 2018.

Accepted for publication: 31 July 2018.

This work is licensed under a Creative Commons AttributionNonCommercial 4.0 International License (CC BY-NC 4.0).

(C) Copyright R. Velezmoro, 2018

Licensee PAGEPress, Italy

Health Psychology Research 2018; 6:7396

doi:10.4081/hpr.2018.7393
Dann, Wolff, \& Brienza, 2014). The silos approach frequently resulted in fragmented outcomes, medical errors, and less than ideal patient care (Goodrich, Kilbourne, Nord, \& Bauer, 2013; Mann, Cronk, Gale, Hogan, \& Washington, 2016; The Joint Commission, 2012). A movement away from the silos approach is occurring with team-based care (Beacham et al., 2017). At the heart of team-based care is the patient-centered medical home $(\mathrm{PCMH})$ model that focuses on an interdisciplinary approach with the goal to improve access, care coordination, and patientprovider communication (Gilman, Chokshi, Bowen, Rugen, \& Cox, 2014). This team approach has been noted to be beneficial across a broad range of illnesses and settings (Galvin, Valois, \& Zweig, 2014; Pape et al., 2011; Proia et al., 2014; Tuepker et al., 2017). This change has also opened a doorway for psychologists to assist in addressing mental health issues within primary care settings and to serve as leaders in the transition to a team-based approach (Beacham et al., 2017; Kazak, Nash, Hiroto, \& Kaslow, 2017). Psychologists are in a unique position to assist in this teambased care (McDaniel \& Fogarty, 2009) due to the multiple roles they can serve (Kazak et al., 2017) as clinicians, team-builders, and system specialists.

Taking a team or a holistic view of a patient means that medical issues are addressed as they intersect with social, emotional, and legal needs (Zeiss, 2016). Hence, team-based care focuses on meeting the needs of the patient within a series of intertwined systems that require careful examination. Team-based care is particularly helpful in providing care to an aging population and within an increasingly complicated medical system (Bodenheimer, 2006; Bodenheimer, Chen, \& Bennett, 2009; Rodriguez, Chen, Martinez, \& Friedberg, 2016). A single provider may struggle to fully help a patient given the complexity of the healthcare system.

Additionally, interdisciplinary team approaches not only improve quality of care but also perceptions of care among patients (Carter et al., 2009).

Team-based care has been of crucial importance in primary care settings, due to the many demands it brings. In fact, the multiple needs of a patient frequently come to the surface in a primary care setting. The Primary Care Physician (PCP) can be seen as the director of care, orchestrating possible solutions to many different issues. In the Veterans Administration (VA), PCPs are tasked with a particularly challenging responsibility due to a large illness burden among Veterans (Agha, Lofgren, VanRuiswyk, \& Layde, 2000; Ginzburg, Ein-Dor, \& Solomon, 2010). In other words, Veterans have been found to have a greater number of both physical and psychiatric illnesses than those in the community (Ginzburg et al., 2010; Hoge, Auchterlonie, \& Milliken, 2006). Military experiences while deployed frequently result in a higher than normal rate of chronic illnesses, such as chronic pain, and psychiatric disorders (Lew, Tun, \& Cifu, 2009).

To meet the needs of the population, and based on the PCMH 
model, in 2010 the VA implemented the Patient Aligned Care Teams (PACT) model (Klein, 2011; Rosland et al., 2013). This approach has been a cornerstone of care in primary care, and there has been an effort to teach this approach to medical residents (Gilman et al., 2014). The idea is that the VA, as one of the largest medical delivery agencies in the United States (Klein, 2011), is an ideal place to bring an interdisciplinary team approach to improving care. Additionally, considering how many patients are seen in the VA (Kearney, Post, Pomerantz, \& Zeiss, 2014) and the fact that much of the medical training that occurs in the U.S. happens in the VA (VA Celebrates, 2016), teaching the PACT model can likely have a lasting beneficial impact on the broader U.S. medical system. Consistent with the patient-centered medical home, in PACT, a team is typically comprised of a physician, nurse practitioner, registered nurse $(\mathrm{RN})$, licensed practical nurse, and a clerk (Ladebue et al., 2015). This is considered to be the core PACT team. Additional providers may include clinical pharmacists, social workers, nutritionists, and psychologists (Ladebue et al., 2015). With this, at the very least, PACT increases the availability of different providers focused on one patient panel (Rodriguez et al., 2016). At its best, however, it allows for a patient panel to be carefully examined by a collaborative team, resulting in a focus on chronic illness management and prevention, advocacy for unique needs and problems, and viewing the Veteran from a holistic perspective. The team meeting, or huddle, is a great representation of this model given it is the coming together of the full diversity of providers. This daily task is the mechanism in which collaboration occurs. Although psychologists have been working in primary care settings for many years, little research has been devoted to understanding their role (McDaniel \& Fogarty, 2009) and how they can best assist the team. Reviewing the need for mental health within PACT and the specific abilities of psychologists' help underline their utility. Additionally, the huddle, as a representation of the VA PACT, is an ideal place to see the benefit of the psychologist and an ideal place for growth. This paper argues, based on a review of the literature, and experience working in a large primary care clinic, that the inclusion of psychologists within the PACT model and huddle helps improve both care and the team.

\section{Patient aligned care team and mental health}

All healthcare providers are tasked with reducing the burden of mental health illness (Kazdin \& Blase, 2011). This responsibility simply needs to be addressed within primary care.

Many mental health issues present and are treated within this setting in large numbers (Goodrich et al., 2013; Regier, Goldberg, \& Taube, 1978; Wang et al., 2007). Embedding mental health staff within primary care is, therefore, cost-effective and efficient (Goodrich et al., 2013). Patients can quickly be evaluated in the same place they see their physician and do not have to return another day for an appointment. This smooth transition is significant given that many patients do not return or follow-up with specialty care (Unützer, Schoenbaum, Druss, \& Katon, 2006). The ease of evaluation and triaging has to be highlighted (Rodriguez, Meredith, Hamilton, Yano, \& Rubenstein, 2015) since it improves the patient or customer service experience.

Due to the need to address mental health concerns within primary care, the VA broadly implemented Primary Care Mental Health Integration (PC-MHI) in 2008 (Kearney et al., 2014; Veterans Health Administration, 2008). PC-MHI was part of a larger movement to integrate behavioral healthcare within the patient- centered medical home (PCMH; Hunter, \& Goodie, 2012). PCMHI consists of both co-located collaborative care and care management (CM; Kearney et al., 2014; Zeiss \& Karlin, 2008). Colocated collaborative care involves having an embedded mental health professional within primary care setting (VHA, 2008). Care management typically involves nurses that work via telephone on medication monitoring, education, and therapy components (VHA, 2008). Highlighting the importance the VA assigns to this integration, $\mathrm{PC}-\mathrm{MHI}$ research and guidance is driven by The Center for Integrated Health (CIH; Beehler et al., 2015). CIH has been essential in implementing PC-MHI and continues improving the service through research (Kearney et al., 2014). The VA is also currently implementing competency training that with assist all PC-MHI staff members to follow population-based care, and better integrate into PACT.

Research conducted within the VA has found that those who were assessed in primary care by a mental health provider were far more likely to have a mental health follow-up (Bohnert, Pfeiffer, Szymanski, \& McCarthy, 2013). Post-Traumatic Stress Disorder is a common disorder found among Veterans, and this integration of care has been found to be helpful in initiating care and lower rates of hospitalization (Bohnert, Sripada, Mach, \& McCarthy, 2016; Brawer et al., 2011; Randall, Mohr, \& Maynard, 2014). PACT utilization has also been associated with reduced ED visits for Veterans experiencing homelessness (Gundlapalli et al., 2017). These results may be secondary to increased interdisciplinary involvement.

Outside the VA, medical providers in surveys have also noted the benefits of having integrated mental health staff within the primary care clinic (Torrence et al., 2014). Although there are many reasons for these results, it likely speaks to the importance of having a warm and supportive individual that guides the patient and PCP to the appropriate service. With mental health needs, there is a need for a human component. This is best exemplified by the warm hand-off where the VA PCP walks the patient to the mental health provider who is located nearby. This moves away from a cold written consult order placed for another date to a sense of teamwork and collaboration in supporting the Veteran's mental health concerns.

Mental health also has to be viewed within the cultural context it exists in, and for many, this involves examining stigma. Stigma with mental health as it relates to gender and age has been found to be more complicated than originally conceptualized (Gulliver, Griffiths, \& Christensen, 2010). This may particularly true for those who served in the military (Greene-Shortridge, Britt, \& Castro, 2007). Many Veterans frequently decline mental health services due to not wanting to be seen in a mental health building or due to the fear they will be labeled. Veterans often report that mental health records were negatively weighted in the military for promotions, resulting in confidentiality concerns (Sloan, Marx, \& Keane, 2011). As such, many Veterans fear that having mental health records will lead to an adverse judgment and different treatment by medical professionals. Being incorporated within primary care drastically reduces this burden, and the warm hand-off from the PCP helps to ease stigma by making it a normal aspect of seeing a PCP.

Related to this, mental health integration within the teams may be particularly important for suicide prevention. Attention to suicides among Veterans has increased with studies showing suicide rates among Veterans being higher than for their civilian counterparts (Blow et al., 2012). Also, studies have shown that a quarter of Veterans who committed suicide had contact with the VA within a year from their death (Basham et al., 2011). This is one of the 
reasons that primary care is seen as an ideal place to address suicide risk (Ashrafioun, Pigeon, Conner, Leong, \& Oslin, 2016). Veterans may see Primary Care as a safe location to discuss mental health issues. There can be a substantial amount of team anxiety about suicide risk assessment (Graham, Rudd, \& Bryan, 2011). This anxiety is evident in the literature, with some studies showing that community physicians do not routinely ask depressed patients about suicide (Feldman et al., 2007). Others have highlighted how more training might be needed in residencies to improve suicide prevention (McDowell, Lineberry, \& Bostwick, 2011). Hence, mental health staff can help by conducting lethality/suicide assessments and also help in easing the anxiety about suicide risk and assessment. Sometimes consulting with a team member about suicide risk and merely confirming clinical decisions can assist the team. This is consistent with research showing that having access to mental health consultation increased willingness to treat suicidal patients (Graham et al., 2011).

\section{Psychologists in patient aligned care team}

With the adaptation of a team-based or PACT model, there are substantial opportunities for psychologists to grow (Kazak et al., 2017) and highlight their abilities. Psychologists have contributed much to the growth of PACT (Kearney et al., 2014). Broadly and consistent with PC-MHI, psychologists can be helpful in addressing mental health needs, triaging, and providing psychological assessments. As team members of the physicians, psychologists can assist in addressing common behavioral health issues (Kaslow, Kapoor, Dunn, \& Graves, 2015). Weight loss, motivational issues, chronic pain, chronic illness management, and mild substance use/abuse are just some of the problems that can be addressed in PACT. While psychologists are not the only ones who can provide behavioral health consultation (Mann et al., 2016), psychologists' have extensive training in a range of evidenced-based treatments that can be of assistance.

McDaniel and Fogarty (2009) use the acronym TEAMS to discuss what the psychologist can contribute to team-based care. They mention: Teamwork for psychologists' dedication to communication and collaboration, Evidenced-based, for focus on empiricallybased treatments, Attention to affect for being able to manage strong emotions, Mindfulness for promoting self-awareness and self-care, and Systematic perspective for taking a broad view of systems and interpersonal relationships. Additionally, Fisher and Dickinson (2014) discuss five roles psychologists can serve in primary care. They mention that psychologists can serve as behavioral clinicians, assist in patient screening, assessment, and monitoring, develop special programs targeting specific population or issues, serve as clinical consultations to the team, and use system thinking to improve the service. Finally, Kazak et al. (2017) highlight how outside of a clinician, psychologists can serve as consultants, teachers/supervisors, administrators/team leads, and researchers.

Three main roles are highlighted in the literature above: clinician, team-builder, and system specialist. Broadly as clinicians, psychologists are helpful with direct clinical care with treating patients, assessing needs, screening, assisting with crisis situations, and helping to triage. Psychologists' ability to serve as teambuilders comes from an understanding of team formation (Zeiss, 2016) that supports and improves the team. Psychologists can utilize common clinical factors in easing tensions, communicating, and bringing providers together for a better interdisciplinary team.
Other, specific, clinical skills can be beneficial. The idea that psychologists can help reframe, or a view a situation in a more positive light, is important with busy teams in a bureaucratic setting. Utilizing empathy and problem-solving are some of the other clinical skills that can assist teams.

System specialist knowledge applies to both relationships and also of program design, research, and education. This focus on systems is one that is particularly helpful given the need for growth and improvement in PACT. Given the constant change in primary care, there is a need to conduct more programmatic research (Funderuck, Dodmeyer, Hunter, \& Walsh, \& Maisto, 2013). Psychologists have the training in research and program evaluation required to improve care. For example, psychologists can develop program evaluations, measure progress, and develop creative ways of solving problems. Collaborating with other primary care staff members and finding creative ways to conduct and measure treatment is an ideal area for growth.

Additionally, psychologists can design programs for teaching the skills necessary for future psychologists to grow in this field.

All the roles the psychologist serve within primary care combine towards a better customer service experience for the patient. Customer service relates to any activity that increases service quality and satisfaction (Ryan \& Ployhart, 2003). Hence, by providing an easy transition to specialty mental health care, addressing behavioral health/milder emotional issues in the clinic, and being available and open to patients and providers, the patient experience is made easier. Further, by addressing broader system issues through education and leadership, and conducting research, psychologists further improve the experience for the patient before he/she enters the clinic. Health care access discrepancies continue to be an issue throughout the U.S. and psychologists can help to address them (Farber, Ali, Van Sickle, \& Kaslow, 2017; Jones et al., 2016). Through utilization of the skills previously discussed, and a focus on culture and diversity, psychologists can help promote healthcare access (Farber et al., 2017).

\section{The interdisciplinary huddle}

The team huddle can be seen as the cornerstone of PACT. Simply, a huddle is a team meeting. More specifically, it is a ... structured, brief (i.e., 5-15 minutes) routine (i.e., daily or multiple times a day) face-to-face communication of a team's full membership (Rodriguez et al., 2015, p. 287). Huddles can be utilized to address daily panels, address psychosocial situations (i.e., housing, employment, etc.), and address emotional and mental health needs of patients (Rodriguez et al., 2015). At the heart of the huddle is communication (Fogarty \& Schultz, 2010) which reduces confusion among staff members (Hyde, 2008) and is a fundamental component of psychology.

The huddle allows for a way to coordinate medical, behavioral, and psychosocial needs (Cooper \& Meara, 2002; Rodriguez et al. 2015; Rosland et al., 2013). Given the complexity of the VA system, increasing understanding is crucial to proper care. Huddles are also an ideal time for discussing any Veteran issues that were found during panel scrubs. Broadly, scrubbing or reviewing the panel involves increasing efficiency by identifying care coordination needs and any information that is necessary for a successful visit (Ghorob \& Bodenheimer, 2015). Typically, for nursing staff, this may entail ensuring the visit is needed and that labs are complete.

Huddling facilitates communication that allows a team to take 
a pro-active approach to complex patients that increases the likelihood of better patient interactions and outcomes. Given the likelihood of primary care staff members encountering crisis situations, the huddle allows for a pro-active crisis prevention approach (Cooper \& Meara, 2002) and allow problems to surface that the physician may have missed (Cooper \& Meara, 2002; Setaro \& Connolly, 2011). Given the multi-tasking demands of the physician, the huddle allows for an entirely holistic view of the patient. Not surprisingly, this approach has been found to assist in improving patient safety (Leonard, Graham, \& Bonacum, 2004).

Professional deformation is a term that is loosely used to refer to the process by which a person, through adapting to a particular job, environment, or professional training, starts thinking within a particular framework (Langerock, 1915). While this is a positive adaptation, it can be argued that it results in viewing situations from an overly fixed perspective. Fundamentally, the huddle challenges professional deformation by allowing the broadest and most diverse viewpoints on a problem or patient. Different, diverse perspectives may, ultimately, result in more realistic judgment.

A hierarchy can frequently play a role in interdisciplinary teams, and the huddle may allow for a leveling of differences in status, therefore resulting in better communication (Brady et al., 2013; Rodriguez et al., 2015). Rodriguez et al. (2015) found that lower status team members frequently did not feel comfortable addressing or accessing medical staff, reducing their ability to communicate and improve the patient experience. They found that teams who huddled reported better teamwork experience and a better, more supportive climate (Rodriguez et al., 2015).

An equally important component of the huddle is the role it plays in improving the relationships within the team. As has been highlighted by several authors, the huddle allows for different providers to think like a sports team, come together and better problem solve towards a shared mission (Dutka, 2016; Stewart \& Johnson, 2007). Although the bringing together of diverse providers is helpful for patient care directly, current research has highlighted that huddles may also assist in enhancing relationships among staff (Lancaster, Kolakowsky $\square$ Hayner, Kovacich, \& Greer $\square$ Williams, 2015; Provost, Lanham, Leykum, McDaniel, \& Pugh, 2015). Team members come from diverse training and, at times, different viewpoints of patients and problems. A successful huddle allows for time for staff to get to know one another and interact in a meaning, helpful way. Due to the benefit of different outlooks, providers may begin to see the benefit of an interdisciplinary staff as the huddles become an ingrained part of the culture of the clinic. Improved relationships, it follows, allows for providers to feel more comfortable meeting, discussing, and consulting, outside of the huddle.

Research has highlighted how burnout or emotional exhaustion can be a problem for primary care staff, especially physicians (Meredith et al., 2015). Studies on burnout and PACT implementation have been mixed (Nelson et al., 2014; Simonetti et al., 2017) and may speak to the complexities of measuring burnout in complex medical environments. However, social support has been consistently found to be a successful approach to preventing burnout (Awa, Plaumann \& Walter, 2010). Interestingly, one study examined tasks associated with burnout among 327 providers from 23 VAs (Kim et al., 2017). They found that PCPs performing behavioral counseling and self-management education tasks without relying on other team members had higher rates of burnout (Kim et al., 2017). Hence, psychologists are in unique position to help prevent burnout among staff due to their training.

\section{Challenges of the huddle}

Central to successful primary care teams, researchers have found that their needs to be a cultural shift towards improved interdisciplinary care (Ghorob \& Bodenheimer, 2015). The move from a culture of fragmented care to a culture of interdisciplinary care is a challenge (Grace, Rich, Chin, \& Rodriguez, 2016). Mistrust of the skill level of other providers or misperceptions of skill level frequently results in less team-based care (Grace et al., 2016; Solimeo, Ono, Lampman, Paez, \& Stewart, 2015) and possible challenges in huddling.

Timing and organizational issues also pose a serious obstacle to the huddle (Grace et al., 2016). One study found that some physicians polled felt that huddles were inconvenient and did not help with patient care (Rodriguez et al., 2105). Further, some physicians felt that the huddle was not the most convenient way to communicate, with many preferring instant messenger programs or calling (Rodriguez et al., 2105). This is likely secondary to hectic clinics and a lack of predictability in schedules. Even with a particular huddle time in place, with walk-ins, emergencies, and challenging patients, huddles can be a challenge. Without enough time to huddle or too high of a patient load, the huddle time can easily be ignored or tabled. Although phone calls and instant messaging communication are beneficial, they do not offer the same level of broad communication necessary to address systematic issues and concerns

Further, for a huddle to be successful there needs to be strong leadership facilitation (Grace et al., 2016). Institution support through blocking clinic times and increasing training appears essential to the success of the huddle. Shunk, Dulay, Chou, Janson, and O'Brien (2014) highlighted the importance of clear expectations, goals, and guidelines in huddling. This may be particularly true with an interdisciplinary staff. Without proper role expectations, the huddle can quickly sink (Harrod et al., 2016). Providers need be aware of their responsibilities, expectations, and what they need to bring to the huddle. Another concern related to leadership involves proper recruitment and retaining of staff. Without proper staffing, team formation is difficult and huddles are less likely to occur (Helfrich et al., 2016).

Clearly, a dysfunctional team with long-standing factions, with no clear guidelines and expectations, will not improve patient care. Shunk et al. stress the importance of a huddle-coaching program to assist teams by teaching trainees how to huddle. Through didactics, group skill sessions, and coaching they were able to address the many factors of the huddle (i.e., process, relational, contextual, \& organizational; Shunk et al., 2014). For some providers who may not be used to huddling, coaching may be essential.

\section{Practical recommendations}

This paper argues that including psychology into the huddle is beneficial for patient care and the team. The psychologist adds perspective and a holistic view of the social, emotional, and legal issues that intertwine with medical issues. Psychologists also help the team and ultimately improve the customer service experience. These are practical recommendations based on a review of the literature and experiences from a PACT team member in a large clinic. Recommendations highlight psychologists' abilities as a clinician, team-builder, and system specialist and are made for in the huddle and for advocating for both the huddle and for broader cultural change. 


\section{In the huddle}

Psychologists should scrub the panels of their PACTs. For psychologists, scrubbing may involve reviewing the mental health notes of the panel, examining missed mental health appointments, and being on the lookout for opportunities for integrating mental health expertise into their routine care. Additionally, by scrubbing the panel psychologists can utilize previous psychological testing (i.e., MMPI or PAI) to help understand a patient's behavior or address team concerns.

Psychologists should focus on problem-solving during huddles. Finding creative ways of engaging patients in treatment is necessary. This may mean stopping by a patient's PCP appointment, being conveniently available, involving family, or offering availability. Finding ways of opening the door to integrate mental health into routine care for treatment aversive patients' needs to be a focus of the psychologist and team.

Psychologists should utilize the Cognitive Behavioral Therapy (CBT) techniques during the huddle. Utilizing CBT skills is an important tool to interdisciplinary teams (Zeiss, 2016). Reframing or viewing a situation from a different perspective is ideal during the huddle. Psychologists can frequently help frame a problem for the team, allowing one to assist without having to intervene directly.

Psychologists should use the huddle to debrief after a particularly challenging situation. Although debriefing after a challenging patient situation is ideal immediately after the situation, this may not be possible due to other clinical responsibilities.

Psychologists should utilize the huddle to educate their teams. This education can focus on what services psychologists can provide, how to integrate mental health into a patient's routine care, and to review broader mental health services available. Also, the huddle is an ideal time to review policy, discuss changes to clinics or procedure, and discuss issues related to suicide prevention.

Psychologists should use the huddle as a time to reinforce positive deeds and teamwork as it relates to mental health. Congratulating team members for collaboration is beneficial.

\section{Advocating for the huddle}

Psychologists should promote the benefits of the huddle and on the need for protected time for the huddle during leadership meetings.

Psychologists should also serve as huddle champions by coordinating with the team on huddle times, sending email/outlook reminders, making suggestions for ways of improving the huddle, and by helping to bring peers into the huddle who may be resistant.

Psychologists should advocate for huddle coaching (i.e., Shunk et al., 2014). through leadership, help develop huddle coaching/champion programs, and further the education on the benefits of the huddle.

Psychologists should focus on finding ways of measuring and assessing the huddle to meet the needs of their individual location/clinics. For example, sending quarterly surveys examining team cohesion/difficulties within the huddles can help clarify issues.

Psychologists should take the lead in huddling and organizing with different staff members when obstacles arise with PACT. For example, one can hold a mini huddle to enhance collaboration in cases where a larger team huddle does not routinely occur.

\section{Advocating for a cultural shift}

Psychologists should focus on team-building exercises and social activities (i.e., potlucks, birthday celebrations, etc.) that help build team relationships.

Psychologists should concentrate on taking a pro-active approach to patient care and the PACT team. It is very easy to take a passive approach within this model by waiting for consults and hiding both physically and figuratively from engaging and improving care. A cultural shift in care will occur when other providers see and hear psychologists and start to view them as a part of the team. Being in the huddle helps but being seen and proactive produces change.

Psychologists should advocate for a cultural shift by including trainees into the huddles. This teaches trainees the advantages of the huddle, increases different perspectives to huddles, and promotes a new generation to interdisciplinary care. These trainees will hopefully leave entirely focused on collaborating and working as a team.

Psychologists should be on the lookout for opportunities to collaborate on research and program development during huddles. Program evaluation and research ideas can easily develop from discussions that originally started in the huddle; ii) Psychologists should help promote the view that mental health care is a part of routine medical health. This change can happen not just by becoming proactive in PACT and the huddle, but also by providing education and guidance to medical staff. Helping to change the language that is utilized in the clinic can have a surprisingly significant impact. For example, coaching staff members to refer to the psychologist as a team member who can assist them with a particular behavioral problem is more helpful than informing a patient they can be referred to mental health; iii) Psychologists should also promote a cultural shift by personally refining their sense of professional identity to fit this interdisciplinary role. Working in PACT can be different than a more traditional therapy role. Psychologists need to shift their attitudes and perspectives on this change and see it as a great opportunity for growth.

\section{A call to action}

As highlighted by multiple researchers, psychologists have the flexibility to serve multiple roles within primary care (Croghan \& Brown, 2010; Kaslow et al., 2015). This flexibility has already assisted psychologists in helping to transform PACT and underlines the role psychologists can play in transforming the broader health care system (Kaslow et al., 2015). As stated, it is likely that by focusing and highlighting the roles of clinicians, team-builders, and system specialists, psychologists can do their part in promoting a cultural shift. In particular, the psychologists' team-builder and system specialists roles need to be emphasized. Currently, there is a need to develop training and clinical competencies in primary care (Beacham et al., 2017). Given the increasing focus on teambased care and a focus on a medical model to care, psychologists need to stay relevant. Furthering research and training in primary care may be the vehicle for this change and relevancy.

Creating a cultural shift in care and psychology should be a focus of every psychologist working in primary care. As highlighted in this article, by improving PACT and the huddle, we establish better teams (Lancaster et al., 2015; Zeiss, 2016) and therefore, better care. This is a crucial part of the solution, but psychologists also are tasked with improving training and research in this grow- 
ing field. Zeiss $(2016,2012)$ quotes a saying of his mother and relates it to the new challenge of interdisciplinary care. He notes: Never turn your back on a wave. Similarly, psychologists need to dive in to interdisciplinary care, the huddle, and promoting a cultural shift. As clinicians, team-builders, and system specialists, psychologists are well-prepared for this task. The call is to dive in or risk being left behind.

\section{References}

Agha, Z., Lofgren, R. P., VanRuiswyk, J. V., \& Layde, P. M. (2000). Are patients at Veterans Affairs medical centers sicker?: A comparative analysis of health status and medical resource use. Archives of Internal Medicine, 160(21), 32523257. doi: 10.1001/archinte.160.21.3252

Ashrafioun, L., Pigeon, W. R., Conner, K. R., Leong, S. H., \& Oslin, D. W. (2016). Prevalence and correlates of suicidal ideation and suicide attempts among veterans in primary care referred for a mental health evaluation. Journal of Affective Disorders, 189, 344-350. doi: 10.1016/j.jad.2015.09.014

Awa, W. L., Plaumann, M., \& Walter, U. (2010). Burnout prevention: A review of intervention programs. Patient Education and Counseling, 78(2), 184-190. doi: 10.1016/j.pec.2009.04.008

Basham, C., Denneson, L. M., Millet, L., Shen, X., Duckart, J., \& Dobscha, S. K. (2011). Characteristics and VA health care utilization of US Veterans who completed suicide in Oregon between 2000 and 2005. Suicide and Life-Threatening Behavior, 41(3), 287-296. doi: 10.1111/j.1943278X.2011.00028.x

Beacham, A. O., Van Sickle, K. S., Khatri, P., Ali, M. K., Reimer, D., Farber, E. W., \& Kaslow, N. J. (2017). Meeting evolving workforce needs: Preparing psychologists for leadership in the patient-centered medical home. The American Psychologist, 72, 1, 42-54. doi: 10.1037/a0040458

Beehler, G.P., Funderburk, J.S., King, P.R., Johnson, E.M., Lilienthal., K., Maisto, S.A., ... Wray, L.O. (2015). The Role and Functions of Embedded Behavioral Health Providers in VA Primary Care-Mental Health Integration: Current Evidence and Future Directions for Research [White Paper]. Available from: https:/www.mirecc.va.gov/cihvisn2/Documents/Research/White\%20Paper\%20.pdf. Accessed: April 7, 2017.

Blow, F. C., Bohnert, A. S., Ilgen, M. A., Ignacio, R., McCarthy, J. F., Valenstein, M. M., \& Knox, K. L. (2012). Suicide mortality among patients treated by the Veterans Health Administration from 2000 to 2007. American Journal of Public Health, 102(S1), S98-S104. doi: 10.2105/AJPH.2011.300441

Bodenheimer, T. (2006). Primary care - will it survive? New England Journal of Medicine, 355(9), 861-864. doi: 10.1056/NEJMp068155

Bodenheimer, T., Chen, E., \& Bennett, H. D. (2009). Confronting the growing burden of chronic disease: can the US health care workforce do the job? Health Affairs, 28(1), 64-74. doi: 10.1377/hlthaff.28.1.64

Bohnert, K. M., Pfeiffer, P. N., Szymanski, B. R., \& McCarthy, J. F. (2013). Continuation of care following an initial primary care visit with a mental health diagnosis: differences by receipt of VHA Primary Care-Mental Health Integration services. General Hospital Psychiatry, 35(1), 66-70. doi: 10.1016/j.genhosppsych.2012.09.002
Bohnert, K. M., Sripada, R. K., Mach, J., \& McCarthy, J. F. (2016). Same-Day Integrated Mental Health Care and PTSD Diagnosis and Treatment Among VHA Primary Care Patients With Positive PTSD Screens. Psychiatric Services, 67(1), 94-100. doi: 10.1176/appi.ps.201500035

Brady, P. W., Muething, S., Kotagal, U., Ashby, M., Gallagher, R., Hall, D., ... \& Geiser, M. (2013). Improving situation awareness to reduce unrecognized clinical deterioration and serious safety events. Pediatrics, 131(1), e298-e308. doi: 10.1542/peds.2012-1364

Brawer, P. A., Brugh, A. M., Martielli, R. P., O'Connor, S. P., Mastnak, J., Scherrer, J. F., \& Day, T. E. (2011). Enhancing entrance into PTSD treatment for post-deployment veterans through collaborative/integrative care. Translational Behavioral Medicine, 1(4), 609-614. doi: 10.1007/s13142011-0097-0

Carter, B. L., Ardery, G., Dawson, J. D., James, P. A., Bergus, G. R., Doucette, W. R., ... \& Xu, Y. (2009). Physician and pharmacist collaboration to improve blood pressure control. Archives of Internal Medicine, 169(21), 1996-2002. doi: 10.1001/archinternmed.2009.358

Cooper, R. L., \& Meara, M. E. (2002). The organizational huddle process - optimum results through collaboration. The Health Care Manager, 21(2), 12-16. doi: 10.1097/HMR.0000000000000009

Croghan, T. W., \& Brown, J. D. (2010). Integrating mental health treatment into the patient centered-medical home (AHRQ Publication No. 10-0084-EF). Rockville, MD: Agency for Healthcare Research and Quality.

Dutka, P. (2016). The Huddle: It's not just for football anymore. Nephrology Nursing Journal, 43(2), 161.

Farber, E. W., Ali, M. K., Van Sickle, K. S., \& Kaslow, N. J. (2017). Psychology in patient-centered medical homes: Reducing health disparities and promoting health equity. American Psychologist, 72(1), 28-41. doi: 10.1037/a0040358

Fisher, L., \& Dickinson, W. P. (2014). Psychology and primary care: New collaborations for providing effective care for adults with chronic health conditions. American Psychologist, 69, 4, 355-363. doi: 10.1037/a0036101

Fogarty, C. T., \& Schultz, S. (2010). Team huddles: the role of the primary care educator. The Clinical Teacher, 7(3), 157-160. doi: 10.1111/j.1743-498X.2010.00369.x

Feldman, M. D., Franks, P., Duberstein, P. R., Vannoy, S., Epstein, R., \&Kravitz, R. L. (2007). Let's not talk about it: suicide inquiry in primary care. The Annals of Family Medicine, 5(5), 412-418. doi: 10.1370/afm.719

Funderburk, J. S., Dobmeyer, A. C., Hunter, C. L., Walsh, C. O., \& Maisto, S. A. (2013). Provider practices in the primary care behavioral health $(\mathrm{PCBH})$ model: An initial examination in the Veterans Health Administration and United States Air Force. Families, Systems, \& Health, 31(4), 341-353. doi: 10.1037/a0032770

Galvin, J.E., Valois, L., \& Zweig, Y. (2014). Collaborative transdisciplinary team approach for dementia care. Neurodegenerative Disease Management, 4(6), 455-469. doi: 10.2217/nmt.14.47

Ghorob, A., \& Bodenheimer, T. (2015). Building teams in primary care: A practical guide. Families, Systems, \& Health, 33(3), 182-192. doi: 10.1037/fsh0000120

Ginzburg, K., Ein-Dor, T., \& Solomon, Z. (2010). Comorbidity of posttraumatic stress disorder, anxiety and depression: a 20year longitudinal study of war veterans. Journal of Affective 
Disorders, 123(1), 249-257. doi: 10.1016/j.jad.2009.08.006

Gilman, S. C., Chokshi, D. A., Bowen, J. L., Rugen, K. W., \& Cox, M. (2014). Connecting the dots: Interprofessional health education and delivery system redesign at the Veterans Health Administration. Academic Medicine, 89(8), 1113-1116. doi: 10.1097/ACM.0000000000000312

Goodrich, D. E., Kilbourne, A. M., Nord, K. M., \& Bauer, M. S. (2013). Mental health collaborative care and its role in primary care settings. Current Psychiatry Reports, 15(8), 1-12. doi: 10.1007/s11920-013-0383-2

Grace, S. M., Rich, J., Chin, W., \& Rodriguez, H. P. (2016). Implementing interdisciplinary teams does not necessarily improve primary care practice climate. American Journal of Medical Quality, 31(1), 5-11. doi: $10.1177 / 1062860614550333$

Graham, R. D., Rudd, M. D., \& Bryan, C. J. (2011). Primary care providers' views regarding assessing and treating suicidal patients. Suicide and Life-Threatening Behavior, 41(6), 614623. doi: 10.1111/j.1943-278X.2011.00058.x

Greene-Shortridge, T. M., Britt, T. W., \& Castro, C. A. (2007). The stigma of mental health problems in the military. Military Medicine, 172(2), 157-161. doi: 10.1177/1534765612455227

Gulliver, A., Griffiths, K. M., \& Christensen, H. (2010). Perceived barriers and facilitators to mental health help-seeking in young people: a systematic review. BMC Psychiatry, 10(1), 113. doi: 10.1186/1471-244X-10-113

Gundlapalli, A. V., Redd, A., Bolton, D., Vanneman, M. E., Carter, M. E., Johnson, E., ... \& O'toole, T. P. (2017). Patient-aligned care team engagement to connect Veterans experiencing homelessness with appropriate health care. Medical Care, 55, S104S110. doi: 10.1097/MLR.0000000000000770

Harrod, M., Weston, L. E., Robinson, C., Tremblay, A., Greenstone, C. L., \& Forman, J. (2016). It goes beyond good camaraderie": A qualitative study of the process of becoming an interprofessional healthcare "teamlet."Journal of Interprofessional Care, 30(3), 295-300. doi: 10.3109/13561820.2015.1130028

Helfrich, C. D., Sylling, P. W., Gale, R. C., Mohr, D. C., Stockdale, S. E., Joos, S., ... \& Nelson, K. M. (2016). The facilitators and barriers associated with implementation of a patient-centered medical home in VHA. Implementation Science, 11(1), 24. doi: 10.1186/s13012-016-0386-6

Hoge, C. W., Auchterlonie, J. L., \& Milliken, C. S. (2006). Mental health problems, use of mental health services, and attrition from military service after returning from deployment to Iraq or Afghanistan. Jama, 295(9), 1023-1032. doi: 10.1001/jama.295.9.1023

Hunter, C. L., \& Goodie, J. L. (2012). Behavioral health in the Department of Defense Patient-Centered Medical Home: history, finance, policy, work force development, and evaluation. Translational Behavioral Medicine, 2(3), 355-363. doi: 10.1007/s13142-012-0142-7

Hyde, P. (2008). Implementing the "Cardiac Huddle." Critical Care Nurse, 28(2), 144-144.

Jones, A. L., Mor, M. K., Cashy, J. P., Gordon, A. J., Haas, G. L., Schaefer, J. H., \& Hausmann, L. R. (2016). Racial/ethnic differences in primary care experiences in patient-centered medical homes among Veterans with mental health and substance use disorders. Journal of General Internal Medicine, 31(12), 1435-1443. doi: 10.1007/s11606-016-3776-1

Kaslow, N. J., Kapoor, S., Dunn, S. E., \& Graves, C. C. (2015). Psychologists' contributions to patient-centered medical homes. Journal of Clinical Psychology in Medical Settings,
22(4), 199-212. doi: 10.1007/s10880-015-9445-4

Kazak, A. E., Nash, J. M., Hiroto, K., \& Kaslow, N. J. (2017). Psychologists in patient-centered medical homes (PCMHs): Roles, evidence, opportunities, and challenges. American Psychologist, 72, 1, 1-12. doi: 10.1037/a0040382

Kazdin, A. E., \& Blase, S. L. (2011). Rebooting psychotherapy research and practice to reduce the burden of mental illness. Perspectives on Psychological Science, 6(1), 21-37. doi: 10.1177/1745691610393527

Kearney, L. K., Post, E. P., Pomerantz, A. S., \& Zeiss, A. M. (2014). Applying the interprofessional patient aligned care team in the Department of Veterans Affairs: Transforming primary care. American Psychologist, 69(4), 399-408. doi: 10.1037/a0035909

Kim, L. Y., Rose, D. E., Soban, L. M., Stockdale, S. E., Meredith, L. S., Edwards, S. T., ... \& Rubenstein, L. V. (2017). Primary care tasks associated with provider burnout: findings from a veterans health administration survey. Journal of General Internal Medicine, 1-7. doi: 10.1007/s11606-017-4188-6

Klein, S. (2011) The veteran's health administration: implementing patient-centered medical homes in the nation's largest integrated delivery system. The Commonwealth Fund, 1537(16), 1-23. doi: 10.1007/s11606-014-2773-5f

Ladebue, A. C., Helfrich, C. D., Gerdes, Z. T., Fihn, S. D., Nelson, K. M., \& Sayre, G. G. (2015). The experience of Patient Aligned Care Team (PACT) members. Health Care Management Review, 41(1), 2-10. doi: 10.1097/HMR.0000000000000048

Lancaster, G., Kolakowsky $\square$ Hayner, S., Kovacich, J., \& Greer $\square$ Williams, N. (2015). Interdisciplinary communication and collaboration among physicians, nurses, and unlicensed assistive personnel. Journal of Nursing Scholarship, 47(3), 275-284. doi: 10.1111/jnu.12130

Langerock, H. (1915). Professionalism: A study in professional deformation. American Journal of Sociology, 21(1), 30-44.

Leonard, M., Graham, S., \& Bonacum, D. (2004). The human factor: the critical importance of effective teamwork and communication in providing safe care. Quality and Safety in Health Care, 13(suppl 1), i85-i90. doi: 10.1136/qshc.2004.010033

Lew, H. L., Tun, C., \& Cifu, D. X. (2009). Prevalence of chronic pain, posttraumatic stress disorder, and persistent postconcussive symptoms in OIF/OEF veterans: polytrauma clinical triad. Journal of Rehabilitation Research and Development, 46(6), 697-702.

Long, T., Dann, S., Wolff, M. L., \& Brienza, R. S. (2014). Moving from silos to teamwork: integration of interprofessional trainees into a medical home model. Journal of Interprofessional Care, 28(5), 473-474. doi: 10.3109/ 13561820.2014.891575

Mann, C. C., Golden, J. H., Cronk, N. J., Gale, J. K., Hogan, T., \& Washington, K. T. (2016). Social Workers as Behavioral Health Consultants in the Primary Care Clinic. Health \& Social Work, 41(3),196-200. doi: 10.1093/hsw/hlw027

McDaniel, S. H., \& Fogarty, C. T. (2009). What primary care psychology has to offer the patient-centered medical home. Professional Psychology: Research and Practice, 40(5), 483492. doi: 10.1037/a0016751

McDowell, A. K., Lineberry, T. W., \& Bostwick, J. M. (2011). Practical suicide-risk management for the busy primary care physician. Mayo Clinic, 86(8), 792-800. doi: 10.4065/mcp.2011.0076

Meredith, L. S., Hackbarth, N. S., Darling, J., Rodriguez, H. P., Stockdale, S. E., Cordasco, K. M., ... \& Rubenstein, L. V. 
(2015). Emotional exhaustion in primary care during early implementation of the VA's medical home transformation: Patient-aligned Care Team (PACT). Medical Care, 53(3), 253260. doi: 10.1097/MLR.0000000000000303

Nelson, K. M., Helfrich, C., Sun, H., Hebert, P. L., Liu, C. F., Dolan, E., ... \& Sanders, W. (2014). Implementation of the patient-centered medical home in the Veterans Health Administration: associations with patient satisfaction, quality of care, staff burnout, and hospital and emergency department use. JAMA internal medicine, 174(8), 1350-1358. doi: 10.1001/jamainternmed.2014.2488

Pape, G. A., Hunt, J. S., Butler, K. L., Siemienczuk, J., LeBlanc, B. H., Gillanders, W., ... \& Bonin, K. (2011). Team-based care approach to cholesterol management in diabetes mellitus: twoyear cluster randomized controlled trial. Archives of Internal Medicine, 171(16), 1480-1486. doi: 10.1001/ archinternmed.2011.417

Proia, K. K., Thota, A. B., Njie, G. J., Finnie, R. K., Hopkins, D. P., Mukhtar, Q., ... \& Lackland, D. T. (2014). Team-based care and improved blood pressure control: a community guide systematic review. American Journal of Preventive Medicine, 47(1), 86-99. doi: 10.1016/j.amepre.2014.03.004

Provost, S. M., Lanham, H. J., Leykum, L. K., McDaniel Jr, R. R., \& Pugh, J. (2015). Health care huddles: Managing complexity to achieve high reliability. Health Care Management Review, 40(1), 2-12. doi: 10.1097/HMR.0000000000000009

Randall, I., Mohr, D. C., \& Maynard, C. (2014). VHA Patient Centered Medical Home Associated With Lower Rate of Hospitalizations and Specialty Care Among Veterans With Posttraumatic Stress Disorder. Journal for Healthcare Quality, 39(3), 168-176. doi: 10.1111/jhq.12092

Regier, D., Goldberg, I., \& Taube, C. (1978). The de facto US mental health and addictive disorders service system. Archives of General Psychiatry, 35, 685-693.

Rodriguez, H. P., Chen, X., Martinez, A. E., \& Friedberg, M. W. (2016). Availability of primary care team members can improve teamwork and readiness for change. Health Care Management Review, 41(4), 286-295. doi: 10.1097/HMR.0000000000000082

Rodriguez, H. P., Meredith, L. S., Hamilton, A. B., Yano, E. M., \& Rubenstein, L. V. (2015). Huddle up!: the adoption and use of structured team communication for VA medical home implementation. Health Care Management Review, 40(4), 286-299. doi: 10.1097/HMR.0000000000000036

Rosland, A. M., Nelson, K., Sun, H., Dolan, E. D., Maynard, C., Bryson, C., ... \& Schectman, G. (2013). The patient-centered medical home in the Veterans Health Administration. The American Journal of Managed Care, 19(7), e263-72.

Ryan, A. M., \& Ployhart, R. E. (2003). Customer service behavior. In W.C. Borman, D.R., Ilgen, R.J. Klimoski (eds). Handbook of psychology: Industrial and organizational psychology, Vol.
12. (377-400). Hoboken, NJ, US: John Wiley \& Sons, Inc.

Setaro, J., \& Connolly, M. (2011). Safety huddles in the PACU: when a patient self-medicates. Journal of PeriAnesthesia Nursing, 26(2), 96-102. doi: 10.1097/ HMR.0000000000000009

Shunk, R., Dulay, M., Chou, C. L., Janson, S., \& O’Brien, B. C. (2014). Huddle-coaching: a dynamic intervention for trainees and staff to support team-based care. Academic Medicine, 89(2), 244-250. doi: 10.1097/ACM.0000000000000104

Simonetti, J. A., Sylling, P. W., Nelson, K., Taylor, L., Mohr, D. C., Curtis, I., ... \& Helfrich, C. D. (2017). Patient-Centered Medical Home Implementation and Burnout among VA Primary Care Employees. The Journal of ambulatory care management, 40(2), 158-166. doi: 10.1097 /JAC.0000000000000160

Sloan, D. M., Marx, B. P., \& Keane, T. M. (2011). Reducing the burden of mental illness in military veterans: Commentary on Kazdin and Blase (2011). Perspectives on Psychological Science, 6(5), 503-506. doi: 10.1177/1745691611416995

Solimeo, S. L., Ono, S. S., Lampman, M. A., Paez, M. B., \& Stewart, G. L. (2015). The empowerment paradox as a central challenge to patient centered medical home implementation in the veteran's health administration. Journal of Interprofessional Care, 29(1), 26-33. doi: 10.3109/ 13561820.2014 .937480

Stewart, E. E., \& Johnson, B. C. (2007). Huddles: Improve office efficiency in mere minutes. Family Practice Management, 14(6), 27-29.

The Joint Commission. (2012). In improving patient and worker safety: opportunities for synergy collaboration and innovation. Available from http://www.jointcommission.org/

Torrence, N. D., Mueller, A. E., Ilem, A. A., Renn, B. N., DeSantis, B., \& Segal, D. L. (2014). Medical provider attitudes about behavioral health consultants in integrated primary care: A preliminary study. Families, Systems, \& Health, 32(4), 426-432. doi: $10.1037 /$ fsh0000078

Tuepker, A., Newell, S., Nicolaidis, C., Reyes, M. E., GonzálezPrats, M. C., Skaperdas, E., \& Kansagara, D. (2017). Veteran patient perspectives and experiences during implementation of a Patient-Centered Medical Home Model. Journal of Patient Experience. doi: 10.1177/2374373517731602

Unützer, J., Schoenbaum, M., Druss, B. G., \& Katon, W. J. (2006). Transforming mental health care at the interface with general medicine: report for the presidents commission. Psychiatric Services, 57(1), 37-47. doi: 10.1176/appi.ps.57.1.37

Veterans Health Administration. (2008). Uniform mental health services in VA medical centers and clinics (VHA Handbook 1600.01). Washington, DC: Department of Veterans Affairs.

VA Celebrates 70 Years of Partnering with Medical Schools (2016). Available from https://www.va.gov/opa/pressrel/pressrelease.cfm? $\mathrm{id}=2747$ 